\title{
COMENTARIO FILOLÓGICO DE UN TEXTO LITERARIO FRANCÉS
}

Maria Paz Aguado Boto

$U N E D$

\section{INTRODUCCIÓN}

Con el presente comentario pretendemos ofrecer un ejemplo de las posibilidades lingüísticas que desde el punto de vista diacrónico encierra, para su análisis, un texto románico.

El método seguido, como puede constatarse fácilmente, ha consistido en deslindar nítidamente los tres niveles del lenguaje: fonético, morfosintáctico y semántico (en el actual trabajo sólo nos ocupamos de los dos últimos, debido a problemas de extensión, relegando el fonético para una posterior publicación) y dentro de cada uno de ellos hemos fijado nuestra atención en aquellos fenómenos que ofrecen una particularidad diferenciadora del idioma sobre el que trabajamos (en este caso, el francés) remitiendo con frecuencia al español, con objeto de aclarar todo lo posible la constatación de las diferentes soluciones dadas a lo largo de toda la Romania a un determinado hecho de lenguaje.

\section{TEXTO}

Tous les jours, le soleil qui tournait sur la colline [...] les laissait dans l'ombre. En face et par-derrière, les pentes grises du terrain remontaient, couvertes de cailloux tachetés d'un rare lichen, et, sur leurs têtes, le ciel, 
continuellement pur, s'étalait, plus lisse et froid à l'oeil qu'une coupole de métal.

FlauberT, Gustave.-Salammbô

\section{NiVEL MORFOSINTÁCTICO}

\subsection{Artículo}

Las lenguas románicas desarrollaron una categoría gramatical, inexistente en latín que tenía como cualidad inherente la de aparecer en el discurso determinando al substantivo. Hablamos del artículo, ya conocido por los griegos, que supone, según Wartburg, una de las manifestaciones más curiosas de la tendencia al análisis de las lenguas románicas a descomponer las formas sintéticas.

No vamos a tratar aquí el problema de su origen. Sólo destacaremos el excesivo uso que ya el latín vulgar hizo del demostrativo, obligándole a seguir un doble proceso:

1. Progresiva pérdida de valor significativo de su naturaleza demostrativa latina.

2. Reducción o mutilación fonética: lat. ill e > fr. le, esp. el.

El artículo pierde, pues, su valor mostrativo latinovulgar al pasar a las lenguas romances, pudiéndose aplicar a cualquier substantivo'.

El latín del Bajo Imperio, época, en la que según Wartburg se ha consolidado definitivamente el artículo, sólo lo utiliza con los nombres concretos, coincidiendo en este punto con el francés antiguo y desligándose del moderno en el que el artículo es de uso obligado con cualquier substantivo. El francés antiguo, no obstante, podía hacer excepciones e individualizar los nombres abstractos con la sola presencia del artículo ${ }^{2}$.

La transformación de los demostrativos en artículos presupone un cambio formal en sus posibilidades combinatorias: el latín i l l e y u n u s no

' Alonso, A.: Estudios lingüisticos. Temas españoles, Ed. Gredos, Madrid, 1982, pp. 131132. Hjelmslev, L.: «La nature du pronom», en Mélanges, I, V, Ginneken, Paris, 1937. La- . míquiz, V.: «El demostrativo en español y en francés. Estudio comparativo y estructuración», en R.F.E., L, Madrid, 1967, pp. 163-202. Lapesa, R.: "Del demostrativo al articulo", en N.R.F.H., XV, Méjico, 1961, pp. 23-44.

2 Lapesa, R.: "Del demostrativo al artículo", en N.R.F.H., XV, Méjico, p. 23. Wartburg, W.: Evolución y estructura de la lengua francesa (Traducción española de Carmen Chust), Biblioteca Románica Hispánica, Ed. Gredos, Madrid, 1966, pp. 43-44. 
exigían la presencia de un nombre. En cambio, en las lenguas románicas los artículos no pueden ir solos como representantes de un grupo nominal íntegro. Véase en el texto: les jours, le soleil, la colline, l'ombre, les pentes grises du terrain, un rare lichen, le ciel, l'oeil, une coupole.

La colocación del artículo, tanto en francés como en español, es ante el substantivo, o ante el sintagma adjetivo más substantivo.

Con las preposiciones $d e, \grave{a}$, el artículo adopta formas contractas que en francés antiguo eran más numerosas. El español moderno sólo conserva las formas contractas del y al, aunque en la lengua antigua $e l$ se escribía unido a toda preposición terminada en vocal; en Castilla se usó la fusión consonántica para las dos preposiciones con y en, uso que comenzó a escasear a principios del siglo XIII.

Se omite el artículo delante de los nombres que indican origen o materia, hecho que se evidencia en el texto: (coupole de métal) y que es común también a nuestra lengua.

Ya en latín, nos dice Bourciez, el numeral u n u s 'uno, solo', origen del llamado artículo indefinido, se empleó muy pronto sin idea de número y con el valor indeterminado de $\mathrm{q} \mathrm{u}$ i $\mathrm{d} \mathrm{a} \mathrm{m}^{3}$.

Para Wartburg la creación de este artículo corre paralela a la del definido y su empleo, casi general, sin la primitiva significación numeral, se remonta al siglo IV, fecha que coincide con la desaparición de $\mathrm{q} \mathrm{u} \mathrm{i} \mathrm{d} \mathrm{a} \mathrm{m}^{4}$.

De desarrollo más tardío que el definido, tiene un uso poco frecuente en el francés primitivo, sobre todo en plural; aunque a partir del siglo XVI su presencia aumenta, tanto en singular como en plural.

A diferencia del artículo proveniente de i 11 e, que, en cuanto se constituye como tal, se convierte en palabra "vacía" carente de todo significado ${ }^{5}$, el indefinido un guarda su significación y acento ${ }^{6}$. Prueba de ello es su posible sustitución por sinónimos: un rare lichen / certain lichen, une coupole de métal / une coupole quelconque de métal.

Se aprecia, pues, en el texto, que la doble presencia del indefinido en sus dos formas singulares (un, une) muestra una referencia semántica más cercana al valor del latino $\mathrm{q}$ u i $\mathrm{d}$ a $\mathrm{m}$ que al del determinado le. Con ambos se introduce nominalmente un objeto que antes no estaba en la esfera común de atención de los dialogantes; si volvieran a aparecer dichos objetos ya requerirían ser nombrados con el artículo determinado.

${ }^{3}$ Bourciez, E.: Eléments de linguistique romane, Ed. Klincksieck, Paris, 1967, p. $100 \$ 108$.

4 Wartburg, W.: Evolución y..., op. cit., pp. 44-45.

5 Hjelmslev, L.: "La nature du...), op. cit., p. 56.

- Alonso, A.: Estudios..., op. cit., pp. 132-133. 


\subsection{Substàntivo}

En latín el substantivo y el adjetivo poseían morfemas de género, número y caso. En francés moderno el substantivo y el adjetivo sólo varían en género y número. En francés antiguo, también variaban en caso.

El latín distinguía con toda claridad entre formas masculinas, femeninas y neutras; entre formas del singular y del plural; entre los diferentes casos. La flexión era desinencial. Estas desinencias han desaparecido por el papel que han desempeñado las leyes fonéticas: las consonantes, una tras otra, han ido dejando de oírse. Primero en el francés preliterario, acto seguido en el francés antiguo, asistimos a la ruina progresiva y completa del sistema de formas heredado del latín?.

En cuanto al fracaso de la declinación latina en su paso al romance, en este caso concreto al francés, hemos de decir que junto a causas de tipo lingüístico también se dejan sentir otras de tipo social, originadas por la falta de sutileza, por la decadencia intelectual en que se sumerge la Galia tras la invasión bárbara. A diferencia de Italia e Iberia, el latín de la Galia evoluciona a un ritmo más lento y, por lo tanto, la flexión casual se conserva más tiempo.

La declinación clásica se reduce en francés antiguo a dos formas, caracterizadas por la presencia o la ausencia de una $-s$ final:

$\begin{array}{lll} & \text { Singular } & \text { Plural } \\ \text { Caso sujeto: } & \text { mur } s & \text { mur } \\ \text { Caso régimen: } & \text { mur } & \text { mur } s\end{array}$

Esta declinación bicasual, incluso con un tercer caso para algunos pronombres, en la Galia se conserva hasta el siglo XIII, y hemos de suponer que en el resto de la Romania, en el momento de sus primeros testimonios literarios, hubiera ya desaparecido. ${ }^{8}$ No está atestiguada en la Península Ibérica, lo cual contribuyó a una fusión temprana de masculino y neutro de la segunda declinación por la extensión de la desinencia $\varnothing$ en singular y la de $(o) s$ en plural:

esp. cielo $\sim$ cielos, ojos $\sim$ ojos, metal $\sim$ metales.

7 Brunot, F. et Bruneau, Ch.: Précis de grammaire historique de la langue française, Masson et Cie., 1969, p. 130.

${ }^{8}$ Politzer, R. L.: «On the emergence of romance from latin», en Word, V, 1949, pp. 126130. Guiraud, P.: L'ancien français, Paris, Presses Universitaires de France, 1968, pp. 94-95. 
En francés ha sobrevivido en la mayoria de los substantivos el caso régimen.

La extensión de la $-s$ como marca de plural, en las dos lenguas que nos ocupan, a todas las categorías del substantivo, se debió a la supervivencia frente a los otros dos formantes de plural: cero fonético $<-i$, $-2<a$, ya que el primero de ellos existía también en singular y la $a$ era asimismo formante del femenino singular en los substantivos de la $1^{\text {a }}$ declinación. ${ }^{9}$

La pronunciación vulgar del siglo XVI, que en toda Francia tiende a no pronunciar la $-s$, llega a convertirse en normativa en el siglo posterior. No existe, a partir del siglo xVII, distinción fonética entre singualr y plural, si exceptuamos algunas palabras con doble forma. En el texto participan de esta dualidad los substantivos ciel, pl. cieux; oeil, pl. yeux, formas ambas, singular y plural, que aparecen en francés con igual frecuencia. En cambio, la forma plural cailloux, mucho más usual, se impone a su correspondiente singular.

Respecto a los restantes substantivos del texto no realizan oposición singular / plural: jours, soleil, colline, ombre, pentes, terrain, cailloux, lichen, têtes, coupole, métal. No conviene olvidar la «liaison» que actúa en ciertos casos, aunque no se halle ninguno de ellos en nuestro texto.

Tocante a la noción de género, en latín había oposición entre neutro, que poseía declinaciones especiales y se correspondía con el inanimado de los Indoeuropeos, y el masculino-femenino, animado de los Indoeuropeos. De todos es conocida la gran arbitrariedad genérica con la que los nombres habían sido clasificados o encasillados en época tan antigua.

En latín vulgar, el neutro tendía ya a su desaparición y con ello se borró

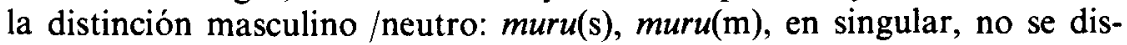
tinguen de foliu(m), foliu(m); en plural, el neutro en - $a$ se confunde, según dijimos con el singular de la primera declinación. El neutro sobrevive únicamente en francés en los pronombres.

La arbitrariedad del género, a la que hemos aludido, se hace manifiesta en todos los substantivos del texto. A veces, ni el determinante de éstos puede esclarecérnoslo, como en el caso de los dos siguientes: l'ombre, l'oeil; les jours, les pentes, cailloux, tachetés, leurs têtes.

Por otra parte, la inseguridad de algunos substantivos en la elección de género, masculino o femenino, ha sido característica de todas las épocas del francés y lo es también de la actual. En muchos casos, el género, al no ser inherente a las cosas, tiene su soporte en el aprendizaje.

' Iordan, I. y Manoliu, M.: Manual de lingüistica románica. Biblioteca Románica Hispánica, Madrid, Ed. Gredos, 1972, V. I, pp. 214-215. 


\subsection{Adjetivo}

«La clasificación de los adjetivos latinos se hizo teniendo en cuenta el número de formas que presentaba el nominativo singular conforme a las diferencias de género. De acuerdo con este criterio, se llevó a cabo la ordenación siguiente: 1) adjetivos de tres determinaciones; 2) de dos terminaciones; 3) de una sola terminación.»

Los adjetivos de tres terminaciones realizaban la oposición masculino / femenino, de mayor importancia en la conciencia de los hablantes que la de animado / inanimado que presentaban los de dos y una sola terminación. De ahí la gran extensión de los adjetivos terminados en -u s, -a, - $\mathrm{u}$ m que a la vez era un reflejo del carácter más regular de las declinaciones primera y segunda.

En el presente fragmento de Flaubert todos los adjetivos que aparecen pertenecen al tipo flexivo -u s, -a, -u m, excepto gris. Se nos presentan repartidos en dos grupos: los variables, con oposición femenino/masculino ( $g r i s,-e$; pur, -e; froid, -e); más abundante en francés que la oposición singular/plural; y los invariables (rare, lisse).

En español, por el contrario, los variables realizan tanto la oposición femenino/masculino, como la de singular/plural (puro, - $a$, os, -as; frio, - $a$, -os, -as; raro, -a, -os, -as; liso, -a, -os, -as), excepto gris que sólo realiza la oposición de número (gris, -es).

Como en español, la anteposición confiere al adjetivo un valor expresivo: rare lichen.

La comparación:

Como nos dice lordan: «Los cambios experimentados por el latín hablado y por las lenguas románicas no afectaron en nada a la substancia semántica de los morfemas de comparación, sino sólo a los formantes y a los términos de las relaciones sintagmáticas obligatorias ${ }^{10}$.

El comparativo de superioridad y el superlativo llegaron a tener un empleo tan frecuente, dado precisamente su gran valor expresivo, que sufrieron un desgaste en el plano semántico; de ahí que se recurriera a la necesidad de buscar otros medios más eficaces para representar esa expresividad perdida. Los que tuvieron mayor fortuna fueron los adverbios de cantidad $\mathrm{m}$ a $\mathrm{g}$ i s como comparativos; $\mathrm{m}$ a $\mathrm{x}$ i $\mathrm{m}$ e, $\mathrm{v}$ a $\mathrm{l} \mathrm{d}$ e, b e $\mathrm{n}$ e, como superlativos, que de hecho también se encontraban en el latín clásico.

Junto a $\mathrm{m}$ a $\mathrm{g}$ i $\mathrm{s}$, en el latín vulgar se empleó $\mathrm{p} 1 \mathrm{u} \mathrm{s}$, formante más moderno, preferido por el francés e italiano, acaso, porque en estas lenguas $\mathrm{m}$ a $\mathrm{g}$ i s se convirtió en conjunción (fr. mais, it. ma). En cambio, el español conservó $\mathrm{m}$ a $\mathrm{g}$ i s junto con el rumano y portugués. En este campo de la

${ }^{10}$ Iordan, I. y Manoliu, M.: Manual..., op. cit., T. I, p. 262. 
flexión comparativa adjetival se pone de manifiesto el hecho de que las dos áreas laterales románicas, español y rumano, son conservadoras, pues forman, como acabamos de ver, su comparativo con la forma vulgar más antigua. Así nos lo hace ver Iordan, de acuerdo con la teoría de Bartoli ${ }^{11}$; si bien es cierto que plus aparece documentado en las Glosas emilianenses, en Berceo, junto al menos usado más, y en el manuscrito parisiense del Alexandre ${ }^{12}$.

El complemento del comparativo va introducido en el texto por la conjunción que, heredera del $\mathrm{q}$ u a $\mathrm{m}$ latino, pues se trata de una relación de no inclusión (comparativo de superioridad).

En francés antiguo, el complemento del comparativo se introducía por la conjunción que si dicho complemento era una proposición (Paul est plus savant que n'est Pierre). Si el complemento era un substantivo o pronombre, éste iba introducido por la preposición de (Paul est plus savant de Pierre). Este último tipo de construcción desapareció en el siglo XVI y sólo subsiste cuando el complemento del comparativo es un nombre que indique número (plus de cent fois).

\subsection{Pronombre}

En las lenguas románicas, las formas pronominales latinas han conservado, a diferencia de las restantes partes del discurso, restos de la declinación casual, tal vez dado su carácter múltiple referencial; con ello queremos dar a entender la gran cantidad de elementos conocidos por los hablantes, a los que aluden. Constituyen una economía para el lenguaje, al aparecer un número tan elevado de veces. «Esto los aproxima mucho a la frontera de los morfemas gramaticales y les confiere una notable estabili$\mathrm{dad} »^{13}$.

En el texto aparece una forma en caso oblicuo que representa el antiguo acusativo de tercera persona del plural: les; al ser forma no acentuada perdió su sílaba inicial ya en la época más antigua del francés. Ignoramos cuál sea

"Iordan, I.: «Le roumain et l'espagnol, aires latérales de la latinité», en Revue Roumaine de Linguistique, 1964, I, p. 9.

${ }_{12}$ Menéndez Pidal, R.: Origenes del español. Madrid, Espasa Calpe, 1968, 6." ed., p. 327\$61. Rohlfs, G.: La diferenciación léxica de las lenguas romances, Instituto Miguel de Cervantes, Publicaciones de la R.F.E., XIV, Madrid, 1960. Meyer-Lübke, W.: Grammaire des langues romanes (Trad. Eugene Rabiet), Vol. III, pp. 62-63. Alvar, M., y Pottier, B.: Morfologia histórica del español. Bibl. Románica Hispánica, Madrid, Ed. Gredos, 1983, pp. 84-86\$59.1, 59.1.1, 60 y 328\$2 15.1. Alvar, M.: El dialecto riojano, Madrid, Ed. Gredos, 1976.

${ }_{13}$ Iordan, I. y Manoliu, M.: Op. cit., T. I, p. 279. Lapesa, R.: «Los casos latinos: restos sintácticos y sustitutos en español", en B.R.A.E., XLIV, Madrid, 1964, pp. 57-105. 
el elemento al que haga referencia este pronombre, al no aparecer en el texto; determina al verbo como objeto directo.

El pronombre reflexivo, muy cerca del personal, al desaparecer la diátesis medio-pasiva en el latín tardío se diferenciaba de éste ya en la lengua latina, por no tener nominativo y no variar en función del número. En romance, aparte de las características semánticas y relacionales del latín, este pronombre recibe la función de índice de la diátesis reflexiva, como en el texto nos evidencia s'étalait. Son las formas átonas $m e, t e, s e$ las que asumen este papel, al igual que en español.

El sistema del pronombre posesivo latino estaba formado por los siguientes términos: singular $\mathrm{m}$ e u s, $\mathrm{t} u \mathrm{u} \mathrm{s}$; pl.: $\mathrm{n}$ o s t e $\mathrm{r}$, v e $\mathrm{s} t \mathrm{e} \mathrm{r}$ s u u s, este último, tanto para singular como para plural; sólo podía emplearse cuando el poseedor era idéntico al sujeto de la oración, lo cual lo aproximaba al reflexivo. Si el sujeto era distinto, se empleaba el demostrativo e i u s.

Dado que en el latín vulgar la flexión pronominal se vio muy afectada, en vez de e i u s se formó un genitivo-dativo analógico de i 11 e: *i 11 u i, i $110 \mathrm{rum}$.

El español siguió con las formas derivadas de s u u s, incapaces, como en la lengua originaria, de expresar la distinción entre uno o varios poseedores.

El francés, así como el rumano y el italiano, también adoptaron los continuadores de s u u s, pero sólo para la tercera persona del singular. Para la tercera del plural emplearon los herederos de il 11 o r u m (fr. leur, rum. lor, it. loro aragonés lor), forma tónica que asumió las funciones del antiguo caso dativo. El rumano y el italiano sin distinción entre uno o varios objetos poseídos; el francés, sí.

El antiguo francés sólo conocía la forma lor invariable, ya que leur $(s)$ con $-s$ en plural, la conocemos a partir del siglo XIV.

Nuestra forma aragonesa lur y catalana llur proceden de *illūrum, cuya $\bar{u}$ es analógica de illūjus, illüi ${ }^{14}$.

«En latín, los pronombres interrogativos se diferenciaban de los relativos sólo por la entonación y por la posición». «En francés y en español, los continuadores de $\mathrm{qu}$ i d (interrogativo) y q u e m (acusativo de q u i) se emplean como relativos o como interrogativos»'s ${ }^{15}$.

El relativo qui no tiene flexión casual, al igual que su correspondiente forma española que. Como tal relativo puede hacer función de sujeto y

14 Alvar, M. y Pottier, R.: Op. cit., pp. 100,77. Alvar, M.: El dialecto riojano, Madrid, Ed. Gredos, 1976. Alvar, M.: Estudios sobre el dialecto aragonés, Institución Fernando el Católico, Zaragoza, 1973-78, Vol. I, pp. 103\$55.4. Grandgent, C. H.: Introducción al latín vulgar (Trad. Fco. de B. Moll), Publicaciones de la R.F.E., n. ${ }^{\circ}$ IX, Madrid, 1970, pp. $241 \$ 390$.

is Iordan, I. y Manoliu, M.: Manual..., op. cit., T. I, pp. 306-308, 328-329. 
objeto indirecto, precedido en este último caso de la correspondiente preposición. En el texto realiza la primera de ellas, e introduce una oración subordinada adjetivo-determinativa.

Los pronombres indefinidos en latín podían aparecer solos o con determinantes del substantivo, rasgo funcional que conservan los idiomas románicos. Expresan relaciones entre la totalidad y sus partes. Algunos se refieren a todas las partes de la totalidad, llamándose por ello totalizadores; dentro de éstos, algunos presentan la totalidad como un conjunto continuo, son los integrales (lat. $\mathrm{t}$ o t u s); otros, como un conjunto discontinuo, son los universales (lat. o $\mathrm{m} \mathrm{n} \mathrm{i} \mathrm{s)}{ }^{16}$.

En el texto el indefinido encierra en sí una suma de unidades, heredando, por tanto, el significado del latino o $\mathrm{m} \mathbf{n}$ i s: fr. tous les jours, esp. todos los dias. Su valor está muy próximo al del distributivo: fr. chaque jour, esp. cada dia. Este tipo de construcción exige el artículo entre el indefinido y el substantivo.

\subsection{Verbo}

Las cuatro formas personales verbales que aparecen en el texto corresponden al pretérito imperfecto de indicativo, del que el francés sólo posee una forma, a diferencia del romance común que poseía tres: a $\mathrm{m}$ ā $b \mathrm{a}(\mathrm{m})$, $\mathrm{h}$ a b ẹ b a(m), s e n t ị b a(m), procedentes del latín clásico a m ạ b a m , h a b ẹ b a m, le gẹ b a m, s e n t i ẹ b a m.

En la época preliteraria francesa ya se redujeron a dos únicos tipos, ya que s e $n t$ e $b$ a(m) reemplaza a s e $n t i ̣$ b a(m). Así pues, el francés antiguo tenia dos imperfectos:

A $\mathrm{m} \bar{a} \mathrm{~b} \mathrm{a}(\mathrm{m})>$ ameve en el Este; amoe, amoue, etc., en el Oeste.

$\mathrm{H}$ a $\mathrm{b}$ ẹ(b)a(m) > aveie, avoie.

A partir del siglo XIII, las desinencias -eie, -eies, -eiet; -iiens, -iiez, -eient, triunfaron en todas las conjugaciones ${ }^{17}$.

El indicativo, como bien es sabido, es el modo mediante el cual expresamos la realidad de la acción. Ya en latín, la oposición indicativo/subjuntivo señalaba la diferencia semántica real/irreal o posible. Todos los imperfectos del texto aparecen en tercera persona, la cual se sincretiza en la

${ }^{16}$ García de Diego, V.: «Divergentes latinos», en R.F.E., V., Madrid, 1918, pp. 139-142.

17 Brunot, F. et Bruneau, Ch.: Précis..., op. cit., p. 239. 
mayoría de los casos en francés actual. Las formas verbales de esta lengua raras veces distinguen fonemáticamente la persona. En español, estos sincretismos son menos numerosos (primera y tercera persona del pretérito imperfecto de indicativo). El francés, en el mismo tiempo y en la misma voz, presenta, sin embargo, similitud entre la primera, segunda, tercera de singular y tercera de plural.

En cuanto a la diátesis, sólo se nos presenta un caso digno de ser comentado: s'étalait. Cuando el agente y el objeto eran idénticos, los verbos transitivos con ayuda del reflexivo, desarrollaron una construcción especial, la llamada construcción pronominal, que al construirse con ayuda de la voz activa no es considerada independiente por la mayoría de los gramáticos. Pero queremos llamar la atención sobre un punto: la forma activa y la reflexiva se diferencian también desde el punto de vista combinatorio o sintagmático, puesto que en francés la forma reflexiva de los verbos transitivos construye sus tiempos perfectivos con el auxiliar être, mientras que la activa exige el auxiliar avoir (en el texto sería: le ciel s'était étalé). El español, en ambos contextos, emplearía haber.

Si tratamos el aspecto, diremos que el imperfecto, uno de los tiempos del infectum, era siempre durativo: expresaba la simultaneidad en el pasado, valor aspectual que pervive en las lenguas romances. En francés, la acción pasada pueden expresarla el pretérito indefinido (prétérit défini, según nomenclatura de Guillaume) y el pretérico imperfecto, siendo el primero el preferido de la lengua antigua.

A partir del siglo XIX, por el contrario, los grandes escritores han transformado el imperfecto en un rico medio estilístico del que se sirven muy a menudo. Flaubert logra con él que el ritmo de la frase exprese todas las sensaciones que van deslizándose en el fragmento.

Ciñéndonos a los imperfectos que aparecen en el texto, podemos observar que el segundo de ellos, laissait, expresa una repetición de la acción, con la ayuda del sintagma: indefinido + artículo + substantivo: tous les jours, que le precede. El primero, perteneciente a la proposición adjetiva especificativa, expresa una acción en vías de desarrollo, tournait; el proceso être en train de sería el que mejor calificaría este pasaje ${ }^{18}$. El imperfecto remontaient que aparece en tercer lugar nos da una idea de aumento, debido al prefijo que lo compone; aumento plasmado en la gran altura del sujeto de èste verbo intransitivo. El pronominal s'étalait, utilizado en sentido familiar, bien puede referirse a una acción durativa.

Pasamos a continuación a ocuparnos de las formas de participio presentes en el texto.

Éstas, a diferencia de las anteriores, son las llamadas no personales.

${ }^{18}$ Badia Margarit, A.: «Ensayo de una sintaxis histórica de tiempos. I. El pretérito imperfecto de indicativo", en B.R.A.E., XXVIII, Madrid, 1948, p. 285. 
Los participios pueden ser invariables, $o$, como en el caso que nos ocupa, adjetivos que varien de género y número: couvertes, tachetés.

Aunque para Iordan «... en francés no existe más forma que la del participio de presente» no todos los lingüistas comparten esta afirmación, y así queda patente en el valor pasivo de los que aparecen en el fragmento que comentamos.

El francés antiguo era muy variable en cuanto al uso y concordancia del participio pasivo, ya que éste podía funcionar como adjetivo o como forma verbal. Si funcionaba como adjetivo variable se construía con el auxiliar être: (étaient) couvertes, femenino plural referido al susbtantivo pentes; (étaient) tachetés, masculino plural referido a cailloux. Si funcionaba como forma verbal invariable se construía con avoir. Ésta es la normativa actual que data del siglo Xvi.

\subsection{Adverbio}

«En la Romania occidental abunda el sufijo -mente, ablativo de $\mathrm{m}$ e $\mathrm{n} \mathrm{s}$, $\mathrm{m}$ e $\mathrm{nt}$ i s "manera de pensar, de sentir, comprensión, entendimiento, mente". En combinación con una serie de adjetivos, el ablativo mente adquiría valor modal». Vossler nos dice que su difusión estuvo favorecida por el Cristianismo, opinión en la que insiste Lapesa al referirse a nuestra lengua ${ }^{19}$.

Partiendo del tipo de construcciones: adjetivo en su forma femenina + mente, el segundo elemento del sintagma pierde su valor léxico.

En francés y provenzal antiguos y en español se tenia la noción de que -mente era independiente del adjetivo, ya que cuando aparecían dos adverbios con este sufijo la terminación iba sólo detrás del segundo: esp. Habla lenta y amablemente, también en construcción inversa en provenzal y muy raras veces en español antiguo: falsament e malvada, aunque normal en catalán clásico y en aragonés medieval ${ }^{20}$.

Si bien el adverbio que aparece en el texto, continuellement, añade el sufijo a un adjetivo, la lengua francesa antigua también podía añadirlo $1 .^{\circ}$ : a adjetivos indefinidos: tellement, $2 .^{\circ}:$ a adverbios: ainsiment y $30^{\circ}:$ a substantivos adjetivados bêtement, usos, primero y último, que aún perduran.

19 Iordan, 1. y Manoliu, M.: Manual..., op. cit., T.I., pp. 369-370 §393. Vossler, K.: Metodologia filológica. Madrid, 1930, p. 35. Lapesa, R.: Historia de la Lengua Española, Madrid, Ed. Gredos, 1981, 8." ed., p. 65.

${ }^{20}$ Moll, Fco. de B.: Gramática histórica catalana, Madrid, Ed. Gredos, 1952. Alvar, M.: El dialecto aragonés, Madrid, Ed. Gredos, 1953. Alvar, M. y Mariner, S.: "Latinismos», en E.L.H., T. II, C.S.I.C., Madrid, 1960-1967, pp. 18\$21. Egea, E. R.: Los adverbios terminados en -mente en el español contemporáneo, Publicaciones del Instituto Caro y Cuervo, n. $\mathrm{XLIX}$, Bogotá, 1979. 
El adverbio modal del texto, como es bien notorio, no modifica al verbo sino al determinante del sujeto de la última proposición coordinada: pur.

Para terminar diremos que los adverbios de modo, a raíz de la aparición en romance del sufijo ya mencionado, alcanzaron un desarrollo considerable y su número e importancia aumentan de día en día, tanto en la lengua escrita como en la hablada. Aparecen en el texto otros dos adverbios, ambos de relación, indicando el lugar: en face y par derrière. Son de creación romance y también forman parte del caudal léxico adverbial del español: enfrente, por detrás. El primero se encuentra formado por una frase de substantivo con preposición y revela un cambio de categoría gramatical; el segundo es fruto de la unión de dos preposiciones: par derrière, la última de las cuales se halla constituida a su vez por una preposición y un adverbio latinos: $d$ e $\mathrm{r}$ e $\mathrm{t} \mathrm{r}$, aunque ya no se tenga noción de su composición, que por otro lado no era ajena al latín antiguo o imperial. Como se puede apreciar en ambas formas francesas, la preposición es separable.

Los dos adverbios expresan una subordinación circunstancial con respecto al verbo remontaient, circunstancia que incluyen en su mismo significado.

\subsection{La preposición y la conjunción}

En las partes del discurso debemos distinguir entre substantivo, verbo, adjetivo o adverbio y preposiciones o conjunciones, ya que éstas, llamadas elementos de relación, funcionan como nexos morfosintácticos y carecen del valor semántico característico de las primeras.

Expresan la relación entre un elemento sintáctico cualquiera y su complemento, o término de la preposición —en palabras de Bello- y ya en latín vulgar adquirieron un gran desarrollo, sobre todo las primeras. $\mathrm{Su}$ éxito romance se debe a la ruina de la flexión sintética por las causas que todos conocemos, entre ellas caida de $-m$, confluencia en algunos casos de diversas significaciones... Las preposiciones, al ser átonas, se emplean proclíticamente.

3.7.1. El presente texto nos ofrece una muestra de las transformaciones semánticas que sufrieron algunas preposiciones, en su paso del latín al romance, al adoptar valores que eran propios de los morfemas casuales. Así, de con ablativo adquirió, entre otros, el valor de genitivo de materia: coupole de métal, empleo que aparece en la época primitiva de la lengua francesa y que es común al español ${ }^{21}$.

${ }^{21}$ Pottier, B.: «Espacio y tiempo en el sistema de las preposiciones», en B.d.F.S., VIII, Santiago de Chile, 1954-1955, pp. 347-354. 
De con ablativo asume a su vez el valor de genitivo de posesión: les pentes grises du terrain.

El campo de a (b), sobre todo ante el complemento agente, es invadido por de con ablativo en los sintagmas: couvertes de cailloux, tachetés d'un rare lichen ya desde el latín vulgar y por supuesto desde el francés antiguo, lengua en la que alterna con par, preposición que tuvo mayor éxito en las dos lenguas romances de que nos ocupamos a la hora de expresar el agente, si bien de fue muy frecuente en nuestros clásicos. Lamíquiz nos habla del funcionamiento en oposición binaria de estas dos preposiciones ${ }^{22}$.

La preposición dans, de creación francesa, no existía en la lengua antigua pero se extendió con considerable rapidez hacia mediados del XVI. Se opone a en, realizando una distinción semántica inexistente en latín: dans expresa la inclusión entre dos límites, sin tocarlos, mientras que en expresa la inclusión entre dos límites, tocándolos. El español no presenta esta dualidad; solamente utiliza en.

Sur es heredera del latín s ŭ $\mathrm{p}$ e $\mathrm{r}$ formal y funcionalmente (sur la colline, sur leurs têtes). Su correspondiente española, sobre, ciñéndonos al valor que encierra en este texto, alterna con encima de, tipo de construcción que nuestra lengua ha extendido mucho más que el francés y que consiste, como a simple vista se aprecia, en añadir de a otras preposiciones.

Por último nos ocupamos de una preposición que junto con de es calificada por Brunot como preposición muerta o vacía ${ }^{23}$, es la preposición $\grave{a}$, que una vez que dejó de indicar específicamente el punto de llegada pasó a utilizarse prolíficamente sin ningún valor especial. En el texto introduce un complemento adjetival: plus lisse et froid à l'oeil. En español empleamos la misma preposición con idéntica función, pudiendo sustituirse por para, aunque cuidando los diferentes matices de ambas ${ }^{24}$.

3.7.2. Pasamos ahora al grupo de las conjunciones. En el texto predomina la categoría de las coordinantes, que unen términos de igual función. $\mathrm{La}$ coordinada copulativa e $\mathrm{t}$ aparece en todas las lenguas romances: fr. et; esp. $e, y$; it. $e(d)$; port. $e$; rum. ant. $e$; ret. y sar. $e$; prov. $e(z)$; cat. $i$. Es la conjunción que expresa la adición. El francés antiguo conoció una forma $e$.

En nuestro texto nos encontramos con un caso en que la conjunción $e t$ une dos oraciones, dos elementos predicativos o sintagmas, remontaient y s'étalait, cada uno con sujeto diferente. En los otros dos casos en los que aparece lo hace para unir dos elementos no predicativos, dos componentes de sintagmas: en primer lugar dos adverbios de lugar: en face et par derrière;

22 Lamiquiz, V.: Lingüistica española, Sevilla, 1974, pp. 345-346.

2.3 Brunot, F. et Bruneau, Ch.: Précis..., op. cit., pp. 377-379.

${ }^{24}$ Correas, G.: Arte de la lengua española castellana, ed. E. Alarcos García, Anejo LVI de la R.F.E., Madrid, 1954. 
en segundo dos adjetivos, términos primarios de la comparación: plus lisse et froid à l'oeil. En el primer caso existe entre ambos enunciados una relación semántica de simultaneidad espacial: en face et par derrière, les pentes grises du terrain remontaient..., et, sur leurs têtes, le ciel, continuellement pur s'étalait. En el último de los ejemplos citados, el adverbio comparativo plus no se repite ante el segundo término coordinado, como también es costumbre entre los hablantes de nuestra lengua.

Para cerrar el apartado dedicado a la conjunción fijaremos nuestra atención en la comparativa que, en su forma elidida: plus lisse et froid à l'oeil qu'une coupole de métal. Los términos comparados son equifuncionales: ciel y coupole, este último sujeto de un sobrentendido s'étalerait. Aquí la comparación indica superioridad en la cualidad, cualidad idéntica para los dos substantivos. Los adjetivos van precedidos de un elemento adyacente, $\mathrm{fr}$. plus, esp. más, al cual le corresponde el término o elemento de relación que. El origen de dicha conjunción se remonta a la latina $\mathrm{q}$ u a $\mathrm{m}$, que introducía el complemento del comparativo o referencia de la comparación ${ }^{25}$, función que compartía con el caso ablativo.

3.8. Acabado el análisis de preposiciones y conjunciones, trataremos de dar una visión de conjunto sobre la estructura lingüística del presente fragmento de Flaubert.

Se halla compuesto el texto por dos períodos oracionales separados por pausa. El primero lo constituye una oración que encierra, dependiendo de la principal, una proposición subordinada adjetiva; el segundo está integrado por dos oraciones coordinadas copulativas, la última de las cuales encierra en sí una idea de comparación.

Como es bien sabido la estructura de la oración francesa, en particular el orden de palabras, presenta una gran rigidez. Wartburg insiste en la particularidad sintáctica del francés, expuesta ya por Thurneysen, según el cual el verbo ocupa siempre el segundo lugar de la oración y las demás partes de ésta se agrupan en relación con tal principio, hecho que desconoce el español, ya que el verbo se encuentra indistintamente en todas las posiciones. Esta característica es bien notoria en el texto, como también lo es el que el sujeto de las oraciones que contienen un régimen vaya antepuesto al verbo y el régimen pospuesto, evitando así cualquier error en la interpretación: le soleil... les laissait, les pentes grises... remontaient, le ciel... s'étalait. Es ésta una construcción lógica de la frase, construcción "lineal" la llama Bally, en que cada miembro va perfectamente escalonado en orden a su aparición o realización de los acontecimientos: sujeto as verbo ws complemento principal y cuyo aumento y proliferación son en gran parte causa de

${ }^{25}$ Quilis, A., y Hernández, C.: Curso de lengua española, Valladolid, 1978, pp. 233-235. 
la ruina en la Edad Media de la antigua declinación. No se invierte el orden de las palabras, a no ser excepciones limitadas que cierren el paso a posibles confusiones.

El francés antiguo era más tolerante en cuanto al orden sintáctico se refiere; esta ligereza de la frase medieval era consecuencia directa del tardío empleo de los $\operatorname{casos}^{26}$, posteriormente los gramáticos del XVIII impusieron a la lengua una estructura rígida que el francés moderno trata de evitar en muchas ocasiones, empleando giros, perifrasis, inversiones sujeto-verbo, para conseguir así una mayor expresividad. Tal vez muestra de ello sea la libertad que el autor del texto se toma al iniciar los períodos oracionales por complementos circunstanciales: Tous les jours..., expresando circunstancia temporal; en face et par derrière, expresando circunstancia locativa y finalmente sur leurs têtes, con expresión también de circunstancia de lugar en el espacio. Exceptuamos un caso, la proposición adjetiva iniciada por su correspondiente pronombre relativo con función de sujeto; esta subordinada expresa la dependencia, formando parte de un todo unitario, la oración, de la cual prolonga su sintagma nominal en función de sujeto: le soleil.

Una vez analizada la proposición relativa, pasemos a su principal; en ella vemos que un objeto directo, les, se interpone entre el sujeto y el verbo: le soleil... les laissait dans l'ombre; si no se tratara de un pronombre personal, el objeto aparecería pospuesto, al igual que ocurriría en nuestra lengua. Se sigue, pues, un orden lógico.

Entramos ahora en el segundo periodo oracional. Inmerso en la primera de las coordinadas nos encontramos un primer complemento del sintagma nominal: du terrain, que lleva forzosamente al segundo: couvertes de cailloux, compuesto de un participio y de su agente, a situarlo detrás del verbo: les pentes grises du terrain remontaient, couvertes de cailloux; este participio adjetival extiende su campo de referencia tanto al sujeto pentes como al verbo remontaient. A su vez el complemento agente cailloux va determinado por una construcción similar, participio pasivo más agente tachetés d'un rare lichen.

En la segunda de las coordinadas el sintagma continuellement pur se intercala entre el sujeto y el verbo y a ambos complementa. Asimismo la oración comparativa nos muestra la cualidad del sujeto y la manera de realizarse el verbo pronominal.

Pese a la aparente rigidez y sobriedad de la lengua, el autor logra, por medio de estas leves alteraciones de elementos de que hemos hablado, un fin expresivo o emotivo, por el que siempre se preocupó; para él poder plasmar su estado anímico a través de la palabra era un gran logro.

Para terminar diremos, de una manera muy breve, que el Imperfecto de

${ }^{26}$ Anglade, J.: Grammaire élémentaire de l'ancien français, Paris, Ed. Armand Colin, 1965. Guiraud, P.: op. cit., p. 110. 
Indicativo señorea el texto como tiempo descriptivo por excelencia, cualidad que aprovecha Flaubert para plasmarla deliciosamente en su narración.

\section{Nivel Léxico}

La mayoria de los filólogos han desarrollado sus ideas acerca de la fragmentación lingǘstica de la unidad latina, aportando datos para su conocimiento basados principalmente en la evolución fonética.

Pero la diferenciación de las lenguas románicas no se ciñe únicamente al plano fonético "sino que afectó - acaso de modo más decisivo-al léxicom. De ahí las palabras de Rohlfs cuando afirma que el léxico de una lengua es el que «nos ofrece mejor que cualquiera otra materia la posibilidad de practicar investigaciones científicas basadas en cimientos culturales» o aquellas de Lüdtke: «la historia del léxico es una parte de la historia misma ${ }^{27}$.

4.1. Empezaremos por destacar la gran importancia que durante la Edad Media, sobre todo hasta el siglo XIII aproximadamente, tuvo el proceso de infiltración germánica en la lengua francesa y lo que dicha cultura supuso en la formación del léxico galo.

4.1.1. En el texto se dan cita varios germanismos. En primer lugar, grises, palabra que para Bloch y Wartburg data del siglo XII, probablemente tomada del antiguo occitano $\mathrm{g} r$ i s, y éste, del fráncico $G \mathrm{r}$ î s, con el sentido de 'anciano', 'cano', origen en el que insisten Meyer-Lübke y Dauzat, aunque no se descarta la posibilidad de que se tomara del neerlandés antiguo g r i j s, 'gris'. García de Diego lo conceptúa como 'color de ceniza'. Nuestro Diccionario de Autoridades lo siente voz flamenca o alemana que saldría del verbo $\mathrm{G} r$ i i s e $\mathrm{n}$, que significa 'llorar', "porque los que lloran sus difuntos se visten deste color», añadiendo asi una nota sentimental a las fuentes de dicho vocablo. El hecho que hemos de recordar es que el latín clásico no tenía término genérico alguno para gris (fr. gris, esp. gris, it. grigio...), cosa que también sucede con otros nombres de colores románicos, tales

${ }^{27}$ Rohlfs, G.: Estudios sobre el léxico románico, Biblioteca Románica Hispánica, Ed. Gredos, Madrid, 1979, p. 135 y p. 26. Lüdtke, H.: Historia del léxico románico, Biblioteca Románica Hispánica, Madrid, Ed. Gredos, 1974, p. 31. 
como blanc, blond, brun, bleu, y que este adjetivo forma parte del léxico español gracias a su introducción a través del francés ${ }^{28}$.

4.1.2. Un nuevo germanismo hallamos en el verbo postnominal s'étalait, cuyo étimo originario es el fráncico *s $t$ a 1 . De su procedencia nos hablan Dauzat, Meyer-Lübke y Wartburg entre otros, y del cambio de su primitivo significado de 'posición' al de 'morada', 'asiento', para posteriormente referirse exclusivamente a los animales y poco a poco restringirse a 'escaparate' y 'tabla de carnicería' ${ }^{29}$. Como verbo se halla atestiguado desde el siglo XII con el sentido de 'se poser': 'estar asentado', y desde el XIII con el sentido actual de 'étendre': 'extenderse'. Desconocemos resultados de esta palabra en nuestra lengua, a no ser el substantivo etalaje, de clara procedencia francesa y cuyo significado semántico nos remite al mundo industrial.

4.1.3. Finalmente tenemos ante nosotros tachetés, otro postnominal, derivado de tache y éste, de un préstamo del gótico $t$ a i $\mathrm{k} \mathrm{n} \mathrm{s}$. El substantivo tache junto con el significado de 'souillure': 'mancha', 'mancilla' posee también, desde el siglo XIV al XVII el de 'cualidad buena o mala de una persona', siendo éste el que más se aproxima al español tacha (una persona sin tacha). La forma verbal francesa data, según Wartburg, de $1538 \mathrm{y}$, según Dauzat, de $1539^{30}$.

4.2. Pasamos así a ocuparnos de préstamos procedentes de otras lenguas y nos encontramos con dos italianismos: colline y coupole, que nos hacen evocar las palabras de Wartburg «El Renacimiento abre a Francia a todas las influencias externas. Naturalmente, es el elemento italiano el que saca especial provecho de esta predisposición del francés ${ }^{31}$ y es que, efectivamente, a principios del siglo XVI, esta lengua, en plena ebullición, especialmente en el campo del vocabulario, recibe innumerables préstamos de su país vecino, de los que ya no podrá deshacerse ${ }^{32}$. Casi todos ellos reflejan

${ }^{28}$ Bloch, O. et Wartburg, W.: Dictionnaire étymologique de la langue française, $6^{\mathrm{eme}}$ éd., Presses Universitaires de France, 1975, p. 306. Meyer-Lübke, W.: Romanisches Etymologisches..., op. cit., p. 330. Dauzat, A.; Dubois, J., y Mitterand, H.:Nouveau Dictionnaire étymologique et historique, $3^{\text {eme }}$. éd., Larouse, Paris, 1964. Ullmann, S.: Introducción a la semántica francesa (Trad. y anot. por E. de Bustos Tovar), Publicaciones de la R.F.E., n. ${ }^{\circ}$ XV, C.S.I.C., Madrid, 1965, p. 405.

${ }^{29}$ Dauzat, A., Dubois, J. y Mitterand, H.: Op. cit. Bloch, O. et Wartburg, W.: Op. cit., p. 238. Meyer-Lübke, W.: Romanisches Etymologisches, Wörterbuch, Carl Winters Universitätsbuchhandlung, Heidelberg, 1935, p. 678.

${ }^{30}$ Dauzat, A., Dubois, J. y Mitterand, H.: Op. cit. Bloch, O. et Wartburg, W.: Op. cit., p. 620.

${ }^{31}$ Wartburg, W.: Evolucion y..., op. cit., pp. 167-170.

${ }^{32}$ Grevisse, M.: Le bon usage, $12^{\text {eme }}$. éd. (ref. par A. Goosse), Ed. Duculot, 1968. (Según Grevisse fueron más de ochocientos los italianismos introducidos en esta época.) 
el espíritu,aventurero, descubridor y práctico de una nueva mentalidad, y, así, los franceses aprendieron habilidades y técnicas en el campo de la guerra: colline, en arquitectura: coupole, en artes decorativas, en pintura, música, náutica, en el comercio, en la moda e incluso en la vida social ${ }^{33}$.

4.2.1. El primero que aparece en el texto, colline, del italiano collina, nos lleva a pensar en un derivado de c o 11 e, del latín c o 11 i s. La primera documentación en lengua española, en la que entraría a través del francés ${ }^{34}$, parece datar del siglo XVII, al emplearlo Quiñones de Benavente en 1651; los primeros testimonios pertenecen todos al lenguaje militar, hecho que amplía el campo semántico del vocablo en la actualidad.

4.2.2. El segundo, coupole, "bóveda que cubre un edificio especialmente la capilla mayor de un templo', del italiano cúpola, y éste a su vez de un diminutivo del latín c ù p a, 'cuba', por comparación de forma, entraña un cambio semántico; como puede apreciarse del sentido propio pasa al figurado. Se halla documentado por vez primera en español en 1604, mientras que en francés se retrasa a 1666.

4.3. En cuanto al léxico latino se refiere, trataremos aquellas palabras que para francés y español presentan diferente etimología.

4.3.1. Al ocuparnos del nivel morfosintáctico, quedó visto el problema de la distinta distribución de $\mathrm{m}$ a $\mathrm{g}$ i s y $\mathrm{p} l \mathrm{u}$ s en la Romania. Ya desde tiempos de Varrón y Plauto, en vez del comparativo orgánico, el latín coloquial conocia la perífrasis con $\mathrm{m}$ a $\mathrm{g}$ i s, aceptada en determinados casos por la lengua escrita (magis idoneus); tan sólo a partir del siglo I de nuestra era dicha función pudo ser realizada también por $\mathrm{p} 1 \mathrm{u} \mathrm{s}$. La Península Ibérica y el extremo más oriental de la Romania se deciden por la forma más antigua: rum. mai, port. mais, esp. más y cat. més; Gascuña se acerca más a la Península Ibérica: más; en provenzal antiguo mais se usó muy escasamente en la gradación adjetival, sin embargo, hoy se permite en el provenzal literario: mai riche. Por el contrario, p 1 u s se ha impuesto en Francia, Italia y Retia: plus, piú y plü, respectivamente. También el gallego-portugués antiguo conoció la forma chus $<$ p l u s (empleada una vez por Berceo) e incluso el español antiguo nos ofrece ejemplos en los que se conserva la forma latina, así como el catalán antiguo y dialectal, que posee plus ${ }^{35}$.

"Vossler, K.: Cultura y lengua de Francia, Buenos Aires, Ed. Losada, 1955, pp. 228-233.

14 García de Diego, V.: Diccionario etimológico español e hispánico, 2." ed., Madrid, EspasaCalpe, S. A., 1985.

"Badía Margarit, A.: Gramática histórica catalana. Barcelona, Ed. Noguer, S. A., I95I. Moll, Francisco de B.: Gramática histórica catalana, Madrid, Ed. Gredos, 1952. 
En resumen, recordemos la distribución que hizo Bartoli al hablarnos de la Romania de cuatro miembros:

$\begin{array}{llll}\text { Iberia } & \text { Galia } & \text { Italia } & \text { Dacia } \\ \text { magis } & \text { plus } & \text { plus } & \text { ma g i s6 }\end{array}$

4.3.2. De diferente étimo, pero con raiz idéntica, tenemos en nuestro texto jours, cuya forma nos remite a un adjetivo latino $d \grave{i} u r n o s$, con cambio de categoría gramatical en su paso al romance peninsular. Está documentado en francés desde finales del siglo XI. En español no ha habido ningún cambio, ya que su etimología es ${ }^{*} \mathrm{~d} \bar{i}$ a, uno de los pocos sustantivos que en latín podia ser masculino y femenino y que en nuestra lengua ha conservado el primero de los géneros mencionados, a pesar de su terminación en -a. Diurno lo conservamos como adjetivo culto, junto con sus derivados diuturnidad, diuturno ${ }^{37}$.

4.3.4. Soleil procede de $\mathrm{s}$ ō $\mathrm{l}$ e $\mathrm{m}$ en su forma diminutiva s o 1 I c $\mathrm{c}$ u $\mathrm{l}$ u, sin que haya en ello alteración semántica alguna. En español sol proviene de la forma primitiva latina.

4.3.5. El verbo tournait, latín $\mathrm{t}$ o $\mathrm{r} \mathrm{n}$ a $\mathrm{b}$ a t, se corresponde etimológicamente con el nuestro, de empleo culto, tornar o el italiano tornare; el español prefirió optar por volver, regresar, vocablos que cubren el campo semántico del francés tourner, atestiguado ya en el año 1080 .

4.3.6. Ullmann al hablarnos de motivación fónica y de palabras con valor expresivo o, según terminología de Grammont, palabras expresivas, nos cita los términos sombre y ombre del francés, este último presente en nuestro texto. Cierto es que a veces los sonidos representan impresiones sensoriales distintas de las acústicas o incluso nociones abstractas, fenómenos psíquicos, etc. Esa imitación indirecta se basa en la tendencia lingüística a interpretar sensaciones, en este caso de oscuridad, con ayuda de otras análogas pero dispares: vocales graves o posteriores: la $o$ cerrada y la $u$, que nos evocan sonidos sombrios; asi se da concreción a un concepto abstracto. Como decía Navarro Tomás: «Las palabras, al lado de su significación histórica, poseen la calidad expresiva correspondiente a su comparación fonética» ${ }^{38}$.

*6 Rohlfs, G.: La diferenciacion..., op. cit., p. 143. También del mismo autor: Estudios sobre..., op. cit., p. $252 \S$ I33.1. Bartoli.: Breviario de neolinguistica, Módena, 1928, pp. 63-64.

"Diccionario de Autoridades, Ed. Facsimil, Biblioteca Románica Hispánica, Madrid, Ed. Gredos, 1984, T. II.

"Ullmann, S.: Op. cit., pp. 138-139. Navarro Tomás, T.: Fonologia española, Syracusa, 1946. pp. 112-113. 
El sustantivo ombre, del latín ŭ $\mathrm{m}$ b $\mathrm{r}$ a, se ha conservado en todas las lenguas romances y en nuestro derivado umbria, tan arraigado y fecundo en la toponimia. En español y en portugués añade una $s$ - protética, probablemente debida al influjo del sol y sus derivados o a la existencia de un verbo *sombrar < *soombrar, procedente de un latinismo s ŭ b ŭ $\mathrm{m}$ b r a r e "poner a la sombra' ${ }^{39}$. La forma primitiva ombra es probable que se diese en época antigua, como lo demuestra la existencia de umbrio y umbría, para posteriormente perderse en nuestra lengua.

4.3.7. Pasamos seguidamente al adverbio derrière, clara muestra de pérdida de motivación etimológica que podemos explicar por el desuso de uno o varios elementos de la palabra; desde que rière $<\mathrm{r}$ e $\mathrm{t} \mathrm{r}$ o desapareció de la lengua, no se comprende la segunda parte de derrière, arrière ${ }^{40}$.

4.3.8. El substantivo pentes, documentado en francés desde principios del siglo XIV y procedente del Participio Pasivo vulgar * $\mathrm{p}$ e $\mathrm{n}$ d (i) t a s, cambia de categoría gramatical, al igual que en español, pero recuérdese que en esta lengua se deriva del Participio Presente del clásico p e n d e r e.

4.3.9. Para la etimología de cailloux nos remontamos a una forma primitiva del siglo XII chaillo, caillou ya en el XIII, que representa al gálico *caljo, *caljāvom, cuya radical preindoeuropea *cal significa 'piedra'. En español éste es el vocablo que poseemos, piedra $<\mathrm{p}$ ĕ $\mathrm{t} \mathrm{r}$ a, conservándose como cultismo cálculo, con evidente cambio de su significado, restringido al campo de la medicina.

4.3.10. El adjetivo posesivo leurs, francés antiguo lor, procedente del genitivo i 11 o r u m tuvo vida en nuestra Península, como quedó dicho al tratar el apartado del pronombre; por lo tanto, no vamos a insistir en él; solamente señalar su distinta etimología en español, el posesivo s u u s, cuyos continuadores, lo mismo que en latín, son incapaces de expresar la distinción entre el poseedor singular o plural.

4.3.11. El substantivo têtes procede del latín $\mathrm{t}$ e $\mathrm{s} \mathrm{t}$ a 'vaso de tierra cocida', 'concha', después en el bajo latín 'calavera', que sustituyó al primitivo c a p u t. Asi tête, considerada metáfora jocosa latino-vulgar, fue

${ }^{39}$ Corominas, J., y Pascual, J. A.: Diccionario crítico etimológico castellano e hispánico, Biblioteca Románica Hispánica, Madrid, Ed. Gredos, 1983, Vol. V.

40 Ullmann, S.: Op. cit., p. 157. 
eliminando poco a poco a chef, en su sentido propio, en francés antiguo. Se halla documentada ya en el año 1080 en La Chanson de Roland (teste) ${ }^{41}$.

El viejo c a p u t poseía dos acepciones metafóricas 'fin' y 'primero, maestro'. Se ha conservado como cap en Rumanía, como capo en Italia central y meridional, en zonas muy limitadas de la Italia superior (lombardo $c \dot{o}$, friulano ciaf), en francés meridional cap, en catalán cap y en rético chiau o cheu. El español y el portugués desde sus textos más antiguos sólo conocen c a p u t en este sentido traslaticio (cabo 'fin', 'mango', 'amarra'; expresiones como llevar a cabo, de cabo a rabo, al fin y al cabo...), mientras que cabeza (port. cabeça) ha ocupado su puesto para denominar la parte del cuerpo; su etimología es c a p i t i u m, forma que sustituyó a c a p u $\mathrm{t}$ en el latín vulgar, hispánico, y que designaba la 'abertura que las túnicas tenían para la cabeza', significación con la que se conocía la palabra en la Francia medieval: fr. ant. chavez, prov. cabetz y a la que el español antiguo no fue ajeno: cabezón (documentada en Alonso de Palencia) ${ }^{42}$.

Otros valores, como pueden ser el italiano cavezza 'cabestro', el provenzal antiguo cabessa 'dossier d'un lit', el gascón cabessa 'parte del arado' (con idéntico valor en portugués y en canario y andaluz ${ }^{43}$ ), el prov. cabetz 'cabecera del lecho', permiten suponer que la denominación hispanorrománica de la palabra se ha formado transportando al hombre la expresividad lingüística de las designaciones animales o del mundo inanimado ${ }^{44}$.

Punto de partida de otra sustitución lingüistica, con gran fortuna en diversas lenguas romances, la tenemos en el siglo IV al abandonar t e s $t$ a su valor primitivo de 'vasija de barro' para emplearse con el de 'cráneo', 'tapa de los sesos' (Prudencio, Ausonio). En Francia se cumplió el relevo del viejo chef por teste entre los siglos XII al $\mathrm{XVI}^{45}$ y por influjo francés, testa desalojó a capo del dominio italiano, sobre todo en el Norte, con las únicas excepciones antes mencionadas del lombardo cò y del friulano ciaf. Testa se ha extendido por toda Italia, incluso por La Toscana que, aunque mantiene todavía capo, no desconoce testa y también en siciliano y calabrés: tèsta. En España tiesta, antiguamente en uso (Cid, Berceo, Alexandre), testa, ha sido totalmente desalojada por cabeza; según nuestro Diccionario de Autoridades con un matiz diferenciador entre ambas: Testa designa «La parte superior de la cabeza, desde el nacimiento del pelo, hasta las cejas, que en

^1 Malkiel, Y.: «Los interfijos hispánicos. Problemas de lingüística histórica y estructural», en Miscelánea Homenaje a André Martinet: Estructuralismo e Historia, II, 1958, pp. 139-181. Diccionario de Autoridades, op. cit., T. III. Dauzat, A. Dubois, J., y Mitterand, H.: Op. cit. ss.

${ }_{42}$ Wartburg, W.: Französisches Etymologisches..., op. cit., T. II. Bartoli: Op. cit., pp. 69 y

4. Dias, G.: "Os arados portugueses», en Revista Universitaria, XVI, Coimbra, 1949, p. 246. Alvar, M.: El español de Tenerife, Madrid, C.S.I.C., 1959.

4 Rohlfs, G.: La diferenciación..., op. cit., pp. 89-91.

4s Wartburg, W.: Französisches Etymologisches..., op. cit., T. III. 
los racionales se llama por lo regular frente; y suele tomarse por toda la cabeza. Viene del Latino Testa». Cabeza designa «La parte superior y principal del cuerpo, que comienza desde el cuello hazia arriba, en la qual están colocados los ojos, nariz, boca y orejas, y otras partes. Viene del Latino Caput, que significa esto mismo ${ }^{46}$. Sin embargo, no debemos olvidar que nuestro vocabulario partió de este cultismo testa (término anatómico algo humorístico que de por sí sugiere la terquedad) para enriquecerse con sus muchos compuestos: testera, testero, testerada, testarada, testarazo, testarudo... ${ }^{47}$

Por último diremos que esta misma fuerza impulsora que conduce a la renovación del léxico engendra la sustitución de una voz desgastada, en este caso, por expresiones más vigorosas, y así, tal como chef dio paso a tête, tête, a su vez, en un futuro podria elegir entre bille, boule, caboche, citrouille..., palabras nuevas a las que el pueblo recurre por la motivación semántica que entrañan. La misma suerte podrian correr los términos españoles: chola, camocha, melón, chimenea..., que nos ofrecen todo un abanico de posibilidades.

4.3.12. El adverbio español continuamente, que se corresponde con el francés del texto continuellement, está formado sobre un adjetivo primitivo: c o n t ĭ n u u s, en cambio el francés toma como punto de partida un adjetivo derivado: $c$ o $n \mathrm{t} i \mathrm{n}$ ŭ $\mathrm{u} s+-\mathrm{a} 1 \mathrm{i}$ s.

4.3.13. En el adjetivo lisse tenemos una muestra de expresividad consonántica producida por la líquida $l$ que nos sugiere una impresión de fluencia, incluso si se trata de superficies o sustancias ${ }^{48}$.

4.3.14. La última palabra del texto y última también de nuestro comentario es el cultismo métal, con idéntica etimología en francés y español, el latín m e $\mathrm{t}$ a $11 \mathrm{u} \mathrm{m}$ : 'mina', 'metal', considerado en nuestra lengua como probable préstamo del catalán.

Vemos, finalmente, que en el aspecto léxico, el texto se nos muestra un claro exponente de la composición de las lenguas romances, al estar constituido por un fondo mayoritario de origen latino y perceptibles aportes posteriores, entre los que destacan los germanismos, consecuencia de la penetración de los bárbaros en los últimos tiempos del Imperio. La presencia de italianismos, a su vez, nos evidencia un influjo que la mayor parte de las lenguas románicas ejerce sobre los diferentes idiomas europeos, debido a la

46 Diccionario de Autoridades, op. cit., T. III.

${ }^{47}$ Malkiel, Y.: Op. cit., pp. 139, 181, 184. Diccionario de Autoridades, op. cit., T. III.

${ }^{48}$ Ullmann, S.: Op. cit., p. 153. 
hegemonía cultural y política que los pueblos que las hablan han detentado en los diversos periodos de la Historia.

\section{CONCLUSiOnes}

A manera de sucinta conclusión podemos señalar cómo en las páginas precedentes hemos comentado rasgos lingüísticos propios de la Romania occidental, y, dentro de ella, de una de las lenguas de mayor claridad, según expresara certeramente Wartburg.

Desde el punto de vista morfosintáctico, el hecho que más nos llama la atención es el arranque de un estado moderno del latín, del que ya se hallaban ausentes, por desgaste, formas tales como $\mathrm{m}$ a $\mathrm{g}$ i s sustituida por plus.

En el nivel léxico acabamos de señalar hasta qué extremo el texto nos puede servir de modelo respecto a la formación del vocabulario románico. 